Ageing \& Society 22, 2002, 483-499. (C) 2002 Cambridge University Press

DOI : голог7/Sor44686Xo2008577 Printed in the United Kingdom

\title{
The social and political context of formal dementia care provision
}

\author{
ANTHEA INNES*
}

\begin{abstract}
$A B S T R A C T$
Dementia care is in transition, and the potential exists for a radical reform of the provision of services to people with dementia. Recent developments in Scotland based on the report of the Royal Commission on Long Term Care, With Respect to Old Age, provide an example of the possibilities and opportunities available to governments for creating services based on principles of equity and justice. It is timely therefore to consider the implications of recent government reports for the development of dementia care provision. This paper explores the social and political context of formal dementia care provision and considers the implications of recent government reports for the future. The historical discourses surrounding the term 'dementia', and where and who cares for people with dementia, provide insights into the options available to policy makers. A brief exploration of the economic context of dementia care provision, and of the historically low level of political interest in dementia care, provides a backdrop to recent political initiatives that seek to redress this omission.
\end{abstract}

KEY WORDS - dementia, care, dementia services, policy, Scotland.

\section{Background context}

Dementia and dementia care have until recently been steeped in the medical model of dementia as a progressive and irreversible disease with a prognosis of misery for the 'sufferer' and his or her family. But during the ig8os psychologists became more vocal about their work with dementia sufferers and their family care givers. They highlighted the psychological aspects of dementia and the importance of care giving and care interventions. The raised interest of psychologists coincided with changes in care provision for frail older people. The closure of long-stay geriatric wards, the rise of voluntary and private sector care provision in residential and nursing homes, and the emergence of care in the community (which includes residential and

* Centre for Social Research on Dementia, University of Stirling, Scotland. 
nursing homes), contributed to the developing profile of both dementia and dementia care in the last decades of the twentieth century. These service changes have coincided with conceptual shifts in the discourse about dementia and care provision for those described by the diagnosis of 'dementia'.

\section{What is dementia?}

The discourse of dementia has a long history. Berrios ( I 994: I 5) makes a case for avoiding confusion over the concept and behaviours involved, and for moving forward from the medical model, or what has been coined the 'standard paradigm' of dementia (Kitwood 1997). The focus of the medical model is dementia as a disease and the loss of 'normality' of those afflicted (Bond I998). Neuropathology dominates the medical model with a focus on the declining cognitive abilities of individuals. The World Health Organization (I992) states that the primary requirement for a diagnosis is evidence of decline in memory and thinking which is sufficient to impair personal activities of daily living. If the assumption is that dementia is a progressive decline, attention is placed on the hopelessness of the conditions commonly known as a dementia, and can lead to the conclusion that the experience of dementia is 'a living death' (Woods I989). There has, however, been a slow shift in the image surrounding dementia which has brought us closer to the person with the diagnosis;

Dementia is ... a result of a set of conditions, medically diagnosed, and leading to recognised and measurable behaviour changes in an individual (Edwards I $993: 6)$.

A subtle change from the medical model which focuses on the condition to awareness of changes in the person has become apparent. There is still however a focus on changes in the person, which if interpreted within the standard paradigm would focus on loss of abilities of the person diagnosed.

The socially constructed nature of dementia (Gubrium i 987; Lyman I 989; Harding and Palfry i 997) has led to the application of the label 'demented' to symptoms and behaviours not well understood by those who are not so labelled. By categorising individuals as demented or having one of the numerous forms of neurological impairment commonly known as 'dementia', society can re-impose order onto the situation that is difficult to understand and, in the process, label the person with dementia as different and therefore potentially deviant in 
some way. This process has contributed to the exclusion of the person with dementia from the discourse of dementia care provision.

Numerous critiques of the biomedical model have emerged (Lyman ı 989; Kitwood and Bredin I992; Kitwood r 997; Bond г992; Harding and Palfry i 997), all highlighting the deficiencies of the medical model, such as the difficulty of diagnosis, and the fact that several disease categories fall under the umbrella term of 'dementia'. The critique of the medical model is complemented by the growing awareness of the individuality of those with dementia and their rights as people (Kitwood I 997; Gilleard 200 I ; Innes and Capstick 200 I). This has of course been long recognised, as in The King's Fund ( I 986) statement that persons with dementia should be treated with dignity and respect.

\section{Who cares for people with dementia?}

Of people with dementia, a large number (8o per cent) live in the community (Nolan et al. I 996); this provides a clear rationale for the wealth of literature surrounding family care giving (Ungerson I987; Ineichen I989; Morris et al. I99I). The percentage has remained relatively constant in the last decade, with recent surveys in Scotland, England and Wales suggesting that more than 20 per cent of people with dementia live in institutional care (Audit Commission 2000; Gordon et al. 1997).

The purpose of this paper is to explore the context of formal care provision for people with dementia. It is important, however, to acknowledge the context of paid care within the wider domain of care carried out in the private sphere, as it appears that greater effort and time has been spent exploring informal caregivers' experiences than of those who perform direct front-line care. It is of interest to note that researchers have paid similar attention to the experience of 'professional' paid carers' work, particularly nurses (Jacques and Innes I 998). Recent work has explored care assistants' experience of training programmes (Beck et al. i 999; McCallion et al. I999), but it has also been noted (Innes I 997) that the experiences of front line paid carers, such as care assistants and nursing auxiliaries, have in comparison been neglected or side lined. Notable exceptions are studies by Lee-Treweek ( I 997) and Hockey ( I990). The proportion of people cared for within the community by informal care givers does not fully explain the low level of research interest in low-status paid care workers.

The principal staff groups providing formal care are care assistants, nurses and managers of homes and hospitals and middle management 
within organisations. There is a wealth of seminal and recent literature exploring management and leadership of organisations and institutions (Goffman r96ı; Foucault I973; Handy r993; Dawson r996; Hall I 997), and much is transferable to the residential or nursing home, but these settings themselves have remained relatively unexplored (Bland I 999; Andrews and Phillips 2000; Innes 2000). Nurses' experiences and coping strategies have been well documented (Boeije et al. I997; Jenkins and Allen r998), and many suggestions made about 'sustaining' and recognising the difference nurses can make to residents (Phair I 997; Royal College of Nursing r 997). There has not been a similar swell of support for the care assistant. This can be partially explained by the low status that care assistants have, their lack of qualifications and low remuneration. Popular beliefs about care and care as work also contribute to the low levels of support and recognition for care assistant work. Care has traditionally been perceived as women's work, carried out for low or no pay in the private sphere (Dalley I988; Graham i98 I). It is often assumed that women care out of obligation and/or love. This however hides the position of women within society, and the expectation that women will care, often leading to the identity of a woman being bound up with notions of care (Graham I99I). It is of interest to note that the recent report of the Royal Commission on Long Term Care, With Respect to Old Age ( I 999), similarly undervalues the position of the care assistant by accepting that they will be paid at the level of the minimum wage. It made no challenge to the assumptions surrounding the position of care assistants, nor recommendations to improve the conditions of this work group. Thus the gendered nature of care work at the very least influences the position of the care assistant and the lack of interest in their work and experiences of work. The Royal Commission's acceptance of the lowly nature and stature of dementia care workers, indicated by its view that workers would be paid the minimum wage, further suggests that there will be an absence of action to lead to improvements in care provision experienced by people with dementia.

\section{Where are people with dementia cared for?}

The majority of people with dementia today, as timelessly, live in the community and are cared for by family members (Nolan et al. I996). The Audit Commission (2000: I I) has reported that 34 per cent of people with dementia in England and Wales were in hospital, residential or nursing care in I996. A Scottish study around the same 
time suggested that 45 per cent of people with dementia were living in institutional care (Gordon et al. 1997). Statistics therefore suggest that a significant proportion of people with dementia will require long-stay care and it is predicted that this number will increase over time (Tester I 999). These figures are higher than the family care literature suggests (Nolan et al. I 996). Laing and Buisson ( 1998) note that there has been an increase in private and voluntary sector residential and nursing care provision and a fall in local authority and long-stay NHS hospital provision in the last decade. There have, therefore, been changes in who provides care at a time when the need for residential and nursing care is predicted to increase.

Means and Smith (I 994) provide an account of care provision for 'Cinderella' groups. They suggest that a comprehensive history of care provision for older people is not available due to the invisible nature of family care in the early 2oth century. They suggest that the legacy of the institutionalisation of older people began with the workhouse in the I 8oos. Although workhouses were replaced with Public Assistance Institutes and then residential homes, the name changes did not alter the reality of life in these institutions (Townsend i 962). Regimes and routines prevailed (Goffman I96I) alongside the denial of rights and the exercise of social control by those paid to care (Lawton i 987), resulting in an image of homes as a 'last resort' (Means and Smith I 994). A recent study (Oldman and Quilgars I 999) purports that there may be a limited demand for collective living but that residential care can be a positive choice for older people living at home in the community who feel isolated. A similar positive message about residential care for people with dementia has been advanced (Kitwood et al. I 995), suggesting that residential care can be a rewarding and life giving experience for people with dementia who would not fare well in the community.

\section{How is dementia care financed?}

A rationing process is evident within health care generally (Butler I 999), particularly in relation to the extension of chronic health care and the level of resources made available to care professionals and for specific health care needs. The cost of dementia to society has been described as:

... the value of all goods and services that are given up in order to prevent, diagnose, treat and otherwise cope with dementia (Max I998: 197). 
TAB LE I. Estimated costs of dementia care

\begin{tabular}{|c|c|c|c|}
\hline $\begin{array}{l}\text { Country and year } \\
\text { of estimate }\end{array}$ & Annual total cost & Reference & Methodology \\
\hline Sweden (I99I) & $\mathrm{SEK}_{30.7}$ billion & Wimo et al. (I99I) & Prevalence study \\
\hline Canada (I99I) & $\$ 3.9$ billion & Ostbye and Crosse (I99 I) & $\begin{array}{l}\text { Net economic study of } \\
\text { care in community and } \\
\text { institutions }\end{array}$ \\
\hline England ( $\left(99^{\circ}-\mathrm{I}\right)$ & £io39 million & Gray and Fenn (I99I) & $\begin{array}{l}\text { AD review only review } \\
\text { of published studies }\end{array}$ \\
\hline
\end{tabular}

Adapted from Max (1998: 202), in Wimo et al. (eds) (1998), Health Economics of Dementia.

The estimated costs of dementia are high according to studies in various countries (see Table I). These are of course 'guestimates' based on sparse information. The Royal Commission has recommended that projections of the costs of long-term care should be published at least every five years ( $1999: 8$ ). The costs of dementia care could be projected on the same basis. Max (I998) concludes that the costs of dementia are high and likely to increase over time as more people contract dementia. In addition, the development of drugs that delay the need for residential and nursing home care may further increase the cost of managing the problem. This, however, is not conclusive. As Stewart ( I 998) has argued, the costs of drug therapies in the future may lower health service costs as there would be a delay in the need for residential and nursing home provision which may be more costly. The commonly cited figure for UK health and social services expenditure for services for people with dementia is $£ 3.3$ billion (Kavanagh et al. I993). However, as there are clear gaps at the current time in knowledge of services available and the cost of these services (Royal Commission I 999:42), it is impossible accurately to project future costs and service development needs.

A further difficulty in developing dementia services is the widely held perception that dementia is a condition worse than death (Patrick et al. I994) and therefore, by implication, not a health state that requires resources, as these will not add value or quality to those afflicted. Bond ( 1998 ) describes the cost utility model of evaluating the value of health status and argues that it disadvantages vulnerable groups, in this case people with dementia. If the perception that dementia is worse than death is applied, current utility theories would indeed discriminate against people with dementia.

There are of course alternative approaches to financing health care. Hakansson (I998) provides examples of OECD countries' different 
methods of financing health care. He argues that health care reforms cannot be 'quick fixes' to the problems and that an integrated approach to the finance and organisation of health care is needed in the future. There appear to be possibilities for developing such systems in the UK, through the current fashion for 'joined up' working and thinking promoted by government-the test will be turning the rhetoric into reality. At present it is difficult to ascertain if dementia is perceived by the government as a health or a social care need. The closure of long-stay wards and the increase in voluntary and private care provision funded in the main by social service budgets suggests that a condition traditionally framed within a medical model is now financed through social services. Four in five residents of residential homes and 74 per cent of people in nursing homes are funded by social services (Audit Commission 2000: 73). This change makes the case for adopting a social model of dementia. What could be perceived as a positive move forward in the discourse of dementia may be limited by the funding and resources available to social services.

There do however appear to be positive signs for the future finance of care provision. Following the Royal Commission report, the Scottish Executive examined the way forward in providing free nursing care. The resulting report from the Chief Nursing Officer has announced measures to improve care provision for older people by extending the provision of free nursing care to individuals with greatest need, which specifically includes persons with dementia (Scottish Executive 200 I; Jarvie 200 I).

There are specific aspects of care provision requiring resources at the direct care level, the most pertinent being staff training. Lack of resources creates obstacles for the funding of staff training opportunities. Research has shown the short-term benefits of staff training (Moniz-Cook et al. I 998; Lintern et al. 200o; Innes 2000) and the Royal Commission acknowledged the need for trained staff, yet funding has not been readily available for this purpose. The Audit Commission suggests that specialist dementia care provision may attract higher levels of funding to pay for staff training (2000: 7 I). Similar recommendations for staff training are made in the consultation document produced by the Centre for Policy on Ageing (2000) for the Department of Health on standards for residential and nursing homes. Yet the issue of staff training appears to be viewed as 'cosmetic', and funding is provided only for basic physical care with social care receiving less interest. In the Jarvie Report (200 I) on Free Nursing Care, training is acknowledged as a central issue with a recommendation that: 
Training should be multidisciplinary and multi-agency and involve older people and carers to develop a shared understanding of roles and needs. This should help ensure the necessary cultural change within organizations (200 I : 7).

The report thus provides a basis not only for providing free care for those in most need but also as a prescription for improving care. It recognises that the culture of care needs to be altered if this aim is to be achieved. Further recommendations of the Jarvie report concern single shared assessment tools, resource allocation tools, and the financial mechanisms required to implement free nursing care for people with dementia. It also proposes ways of providing staff with appropriate training to enable them to carry out high quality care. The Scottish Executive recently published Care Standards for Older People (200 I a) which details the framework for the implementation of high quality service provision for all older people.

\section{The politics of dementia care}

Improving the wellbeing of all persons with dementia is difficult because of the 'Alzheimerisation' of dementia (Kitwood r997: 22). The conditions known as dementia have been labelled variously according to terminological fashion, from 'senility' in the early part of the 2oth century, to 'Alzheimer's Disease' in the ig8os (Fox I989). Dementia and dementia care have historically occupied a low position on the political agenda, and there has been little government policy on caring for people with dementia (Sassi and McDaid i999). The absence of a powerful political lobby or forum may have contributed. The English and the Welsh Alzheimer's Societies and their Scottish counterpart, Alzheimer's Scotland Action on Dementia, regularly react to government initiatives (or the lack of them), but their voices appear to have little effect. This may however be set to change, at least in Scotland with the recent election of the chair of the Royal Commission on Long Term Care, Sir Stewart Sutherland, as the president of Alzheimer Scotland Action on Dementia. The British Isles have not cultivated a 'grey power' lobby as in America where it has had the opposite effect to that desired by policy makers: when welfare programmes are introduced, opposition is mounted by wealthier sections of society who stand to lose by the introduction of taxes. Thus Binstock and Murray ( 1992 ) argue that the finance of care is a political question which needs to be answered before more effective dementia services can be developed. If grass roots support is enlisted, they 
suggest, it is more likely that policies will be supported by government officials and by the public. The Scottish Executive's decision to explore new approaches to financing of long term care (Jarvie 200I), and to provide free nursing care, suggests that improvements are possible.

Herskovits (1995) charts the political-economic purposes that the Alzheimer's discourse serves. She argues that if the disease is seen as a living death by society, both politicians and service providers need not concern themselves with quality. Post ( $1993: 67$ ) asserts that there is a moral imperative to evaluate the subjective experience of dementia, given the concurrent debate about euthanasia. If we accept that Alzheimer's disease is a fate worse than death, then assisting people to die (and cutting service costs) does not pose a moral and ethical dilemma. A recent study with general hospital staff and psychiatric staff working with people with dementia found that the latter were more likely to support euthanasia than their general hospital staff counterparts (Armstrong-Esther et al. 1999). Thus there is an imperative to explore the subjective experience of dementia if researchers and practitioners are not to impose their own pervasive concerns with the meaning of Alzheimer's disease ... [and] efforts to grapple with the nature of the relationship between those who are already old ... and those who will yet 'become old in the future' (Herskovits I 995: I48).

Improving service provision for people with dementia and allocating resources to an area lacking glamour and professional prestige is an uphill but not an insurmountable struggle, as the current Scottish experience highlights. Consultation with practitioners across Scotland (Jarvie 200 I, paras 34-47), and the active engagement of the primary Scottish charity representing people with dementia and their carers, Alzheimer Scotland Action on Dementia, is a timely reminder that support for initiatives is required from both policy makers and service users and their representatives (Parsons i 995).

The myth of older people as a burden to society is perpetuated by the media (Biggs I993) and the 'rising tide' image (Ineichen I987), particularly as it is applied to people with dementia. The construction contributes to the unwillingness of politicians to support the improvement of dementia care. The Jarvie report begins to address the first of these issues in the Scottish context. Many people with dementia are likely to end up in nursing or residential care. Thus the recommendation of free provision funded through existing frameworks, as endorsed by the Scottish Executive (200 I b), in a press release stating plans to make long-term care needs of older people a 'top priority for additional resources', is a positive move forward. 
How to ascertain the quality of dementia care has not been adequately addressed by the Jarvie Report, although its recommendation of a single assessment tool to ascertain the holistic needs of the person indicates a move forward in the development of quality person centred dementia care services (paras i6-ig). Further political attention can be expected with the implementation of the National Service Framework for Older People (Department of Health 200I), with its measures to improve quality and decrease inequities in service provision across the UK. It may be that dementia care is on the political agenda and that future people with dementia will benefit.

\section{What constitutes quality dementia care?}

The policy developments in Scotland do not address the important practice issue of how best to ascertain and raise the quality of care offered to persons with dementia. At present there is no consensus about what constitutes quality dementia care and how to assess care provision. This may be explained by two factors: the absence of quality tools with which to measure, monitor and assess dementia care (Bond I999), and the gap between the understanding of 'quality dementia care' and the methods used to evaluate the same.

It has been suggested that supervision mechanisms, staff recruitment systems, and training opportunities in a residential setting may contribute to the provision of quality care (Kitwood and Woods I 996). Similarly, Peace et al. (I 997) have argued that staff must be provided with training if they are to operationalise quality care practice. American authors have devised checklists to assess the quantity and standard of care facilities (Moos and Lemke I984), and similar tools have been developed in the UK (Royal College of Physicians I992; I 999). The logic of monitoring instruments is that a higher quality of care can be attained. This is not necessarily the case. As Harding and Palfry (I997) argue, the basis on which evaluations of dementia services are undertaken may be flawed. If a diagnosis of a dementia means that a person is not consulted about their preferences in a residential setting, it may follow that the criteria for 'quality care' are entirely based upon the 'professional' viewpoint, not that of the person with dementia.

Yet when people with dementia are asked about what they would see as a quality service, answers are forthcoming and include activities within the home, the opportunity to get out of the home, and the provision of good food (Raynes I999). We still have much to learn 
about the viewpoint of persons with dementia. Goldsmith ( I996) has advanced ideas about hearing the voice of people with dementia. His own work, however, is based on talking to only six people with dementia. Other studies have begun to explore the viewpoint of people with dementia (Dabbs I998), but the findings to date are thin. The statements of people with dementia are rarely fully analysed or related to the service in question. Some current work seeks to rectify this gap (Allen and Killick 2000; Innes et al., forthcoming). Thus, attempts could and are being made by many researchers to hear the voices of people with dementia, but speaking to the patients, residents or clients is not widely used to assess the quality of service provision.

A plethora of tools is used to assess quality of care. A review illustrates the different starting points of measurement tools (Brooker I 995). For example, the Patient Behaviour Observation Instrument (PBOI) (Bowie et al. I992) and the Quality of Interaction Scale (QUIS) (Dean et al. I993) both look at the behaviours of people with dementia to ascertain the quality of care in formal settings. The Audit Commission (2000: 8I) recommends that social services departments should monitor the quality of dementia care provision, partly through the views of users and carers. Similarly there is concern throughout the Jarvie report about the quality of services, how to assess quality (appendix 7), and the difficulties of changing cultures of care from organisation-centred to patient-centred (para 57).

Perhaps the missing aspect of many methods is a clear statement of what constitutes quality care. In a paper that documents how to measure quality of care in psychogeriatric wards, Gilloran et al. (I993) outline the overlap between quality of life and quality of care. The authors eventually utilised multiple methods to try to overcome the difficulties of definition and the multi-faceted nature of quality of life and care. There is often a hidden assumption about what quality means. McKee (I 999) argues that if studies investigating quality of life/care do not canvas the views of the users themselves, then the study can only be loosely patient-centred or person-centred (Kitwood and Bredin I992). Current thinking among British researchers appears to be that we should evaluate the extent to which services are patientcentred (Audit Commission 2000; Jarvie 200 I).

Person-centred care was developed to enhance what has been called 'personhood' (Kitwood and Bredin I 992), later defined as 'a standing or status that is bestowed upon one human being by others, in the context of relationship and social being' (Kitwood i 997: 8). 'Dementia Care Mapping' is the observation method which seeks to evaluate whether person-centred care is occurring. 
If personhood is maintained, a sense of social confidence, worth, agency and hope will have been preserved for the person with dementia. In simple terms this means that a person with dementia will be confident to engage with others, will feel valued and accepted by others, be active and participate in activities that have personal meaning, and will retain a sense of purpose. There have been similar conceptual advances in recognising that persons with dementia retain a sense of 'self'. It has been suggested that the concept of the self has similarities to Kitwood's concept of personhood (Innes and Capstick 200 I). Sabat and Harre ( I 992) present a framework for understanding how the sense of self in the person with dementia helps them interpret the actions of others. They argue that the person has two selves. How others interact can enable or deny the self of the person with dementia. Sabat and Collins ( I 999) provide a case of the ways in which multiple 'selves' are upheld by a woman with dementia. She draws upon her life history to preserve a sense of value through acknowledgement of the self. Fontana and Smith ( I 989 ), by contrast, provide examples of the self of a person with dementia not being recognised, as when a participant's attempts to communicate were interpreted as meaningless nonsense and his utterances were dismissed. Therefore the actions of others, both paid and unpaid carers, will influence the self/personhood of the person with dementia and through that their quality of life and wellbeing. Thus, to arrive at a consensual definition of the quality of life or quality of care is a difficult if not impossible task. Whom we ask will influence the response we receive, and the view taken of dementia will in turn influence the expectations one has about the experience of dementia. Herskovits (I995: I59) states that debates about the self have 'disentangled the self from cognitive ability', in sharp contrast to the medical discourse about Alzheimer's disease (and other dementias) which focuses on loss of abilities. The elaboration of theory on the self or personhood of people with dementia is likely to establish a more optimistic vision of 'quality of care' than one which sees dementia as a fate worse than death.

\section{Conclusion}

Complex and diverse factors surround the future direction of dementia care provision in the United Kingdom. These fall into three key areas: social, political and economic. The interplay between these factors is complex and contributes to current attitudes about dementia care. The understanding of dementia by those who provide care varies 
considerably, contributing to a lack of consensus about what constitutes good quality in dementia care.

Social and political factors have combined to influence the reaction to reports of the Royal Commission on Long Term Care and by Jarvie. The low status that society awards to care workers and people with dementia contributes to the low priority that dementia care has occupied on the political agenda. The gendered nature of care work, and the expectation that women will care and do not desire or need to be rewarded for this task is perpetuated by images of women's work. Furthermore, the lack of political influence care workers exercise, partly explained by their historically low rates of organisation in the trade union movement (Grint I99I), may prove a difficult legacy and impede change in the culture of care. Rationing of services, the lack of resources for training care workers, and poor conditions and facilities will continue if there is not a political lobby for change.

There are however positive political moves to advance services for people with dementia. The Jarvie Report suggests a way forward in Scotland that could be applied across the United Kingdom. And researchers and dedicated innovatory care projects are beginning to deepen our understanding of both the experience of the person with dementia, and the ways in which those who interact with and care for them can protect and raise their quality of life.

\section{Acknowledgement}

I would like to thank Colin Bell for his comments on an earlier draft of this paper.

\section{References}

Allen, K. and Killick, J. 200o. Pathways Communication and Dementia Newsletter. Dementia Services Development Centre, University of Stirling, Stirling.

Alzheimer Scotland Action on Dementia 2000. Response to Scottish Executive Draft National Care Service www.alzscot.org/policy/carestandardssubmission.html

Andrews, G. J. and Phillips, D. R. 2000. Moral dilemmas and the management of private residential homes: the impact of care in the community reforms in the UK, Ageing and Society, 2o, 5, 599-622.

Armstrong-Esther, C. A., Browne, K. D. and McAffee, J. G. I 999. Investigation into nursing staff knowledge and attitudes to dementia, International Fournal of Psychiatric Nursing Research, 4, 3, 489-97.

Audit Commission 200o. Forget Me Not: Mental Health Services for Older People. Audit Commission, London.

Beck, C., Ortigara, A., Mercer, S. and Shue, V. i 999. Enabling and empowering nursing assistants for quality dementia care, International Fournal of Geriatric Psychiatry, I4, I 97-2 I 2 . 
Berrios, G. E. I 994. Dementia: historical overview. In Burns, A. and Levy, R. (eds), Dementia. Chapman and Hall Medical, London.

Biggs, S. 1993. Understanding Ageing: Images, Attitudes and Professional Practice. Open University Press, Buckingham.

Binstock, R. H. and Murray, T. H. I992. The politics of developing appropriate care for dementia. In Binstock, R. H., Post, S. G. and Whitehouse, P. J. (eds), Dementia and Ageing: Ethics, Values and Policy Choices. Johns Hopkins University Press, Baltimore.

Bland, R. I999. Independence, privacy and risk: two contrasting approaches to residential care for older people, Ageing and Society, 19, 5, 539-6o.

Boeije, H. R., Niewaard, A. C. and Casparie, A. F. i 997. Coping strategies of enrolled nurses in nursing homes: shifting between organizational imperatives and residents' needs, International Fournal of Nursing Studies, 34, 5, 358-66.

Bond, J. I992. The medicalization of dementia, Fournal of Ageing Studies, 6, 4, 397-403.

Bond, J. I998. Quality of life of people with dementia and their informal caregivers; is this a measurable outcome in clinical trials? Paper for Fifth Annual Conference of the International Society for Quality of Life Research I $5^{-1} 7$ November. Baltimore, Maryland.

Bond, J. i 999. Assessing quality of life for people with dementia, Progress in Neurology and Psychiatry, 3, 29-34.

Bowie, P., Mountain, G. and Clayden, D. i992. Assessing the environmental quality of long stay wards for the confused elderly, International Fournal of Geriatric Psychiatry, 7, 95-I04.

Brooker, D. I 995. Looking at them, looking at me. A review of observational studies into the quality of institutional care for elderly people with dementia, Fournal of Mental Health, 4, I45-56.

Butler, J. I999. The Ethics of Health Care Rationing: Principles and Practices. Cassell, London.

Centre for Policy on Aging 2000. Fit for the Future? National Required Standards for Residential and Nursing Homes for Older People: Consultation Document. Department of Health, London.

Dabbs, C. I999. Please Knock and Come in for Tea. Preston Community Health Council, Preston, Lancashire.

Dalley, G. i988. Ideologies of Caring. Macmillan, Basingstoke, Hampshire.

Dawson, S. 1996. Analysing Organizations. Macmillan Business, London.

Dean, R., Proudfoot, R. and Lindesay, J. i 993. The Quality of Interactions Schedule (QUIS): development, reliability and use in the evaluation of two Domus Units, International Fournal of Geriatric Psychiatry, 8, 8 19-26.

Department of Health 200 i. National Service Framework for Older People. Department of Health, London.

Edwards, A. J. I993. Dementia. Plenum Press, New York.

Fontana, A. and Smith, R. W. i989. Alzheimer's disease victims: the 'unbecoming' of self and the normalization of competence, Sociological Perspectives, 32, I, 35-46.

Foucault, M. 1973. The Birth of the Clinic: An Archaeology of Medical Perception. Tavistock Publications, London.

Fox, P. I989. From senility to Alzheimer's disease: the rise of the Alzheimer's disease movement, Millbank Quarterly, 67, I, 58-102.

Gilleard, J. 200I. The perspectives of people with dementia, their families and their carers. In Cantley, C. (ed.), A Handbook of Dementia Care. Open University Press, Buckingham.

Gilloran, A. J., McGlew, T., McKee, K. et al. i 993. Measuring the quality of care in psychogeriatric wards, Fournal of Advanced Nursing, 18, 269-75. 
Goffman, E. ig6r. Asylums: Essays on the Social Situation of Mental Patients and Other Inmates. Penguin, Harmondsworth, Middlesex.

Goldsmith, M. I 996. Hearing the Voice of People with Dementia. Jessica Kingsley, London.

Gordon, D., Carter, H. and Scott, S. I 997. Profiling the care needs of the population with dementia: a survey in central Scotland, International Fournal of Geriatric Psychiatry, I 2, 753-9.

Graham, H. i98 I. Caring, a labour of love. In Finch, J. and Groves, D. (eds), A Labour of Love: Women's Work and Caring. Routledge and Kegan Paul, London.

Graham, H. I991. The concept of caring in feminist research: the case of domestic service, Sociology, 25, I, 6 I-78.

Grint, K. I99.. The Sociology of Work: An Introduction. Polity Press, London.

Gubrium, J. F. 1987. Structuring and deconstructing the course of illness: the Alzheimer's disease experience, Sociology of Health and Illness, 9, I-24.

Hakansson, S. I998. Different ways of organizing and financing health care. In Wimo, A., Jonsson, B., Karlsson, G. and Winbald, B. (eds), Health Economics of Dementia. John Wiley and Sons, New York.

Hall, R. H. i997. Organizations: Structures, Progresses and Outcomes. Prentice Hall, London.

Handy, C. I993. Understanding Organizations. Penguin, Harmondsworth, Middlesex.

Harding, N. and Palfry, C. I997. The Social Construction of Dementia: Confused Professionals? Jessica Kingsley, London.

Herskovits, E. I995. Struggling over subjectivity: debates about the self and Alzheimer's disease, Medical Anthropology Quarterly, 9, 2, I46-64.

Hockey, J. I990. Experiences of Death. Edinburgh University Press, Edinburgh.

Ineichen, B. I 987 . Measuring the rising tide: how many dementia cases will there be by 200 I? British Fournal of Psychiatry, I5, I 95-200.

Ineichen, B. i 989. Senile Dementia: Policy and Services. Chapman and Hall, London.

Innes, A. I 997. Towards an understanding of care assistants' constructions of residents as difficult. Unpublished MSc thesis, University of Stirling.

Innes, A. 2000. Changing the culture of dementia care: a systematic exploration of the process of cultural change in three care settings. Unpublished $\mathrm{PhD}$ thesis, University of Bradford.

Innes, A. and Capstick, A. 200 I. Communication and personhood. In Cantley, C. (ed.), A Handbook of Dementia Care. Open University Press, Buckingham.

Innes, A., Hodgson, S. and Gallagher, R. Forthcoming. What People with Dementia Think about Support Services. Older Peoples' Programme Report. Joseph Rowntree Foundation, York.

Jacques, I. and Innes, A. I998. Who cares about care assistant work? Journal of Dementia Care, 6, 33-37.

Jarvie, A. 200 I. Report of the Chief Nursing Officer for Scotland's Group on Free Nursing Care. Scottish Executive, Edinburgh.

Jenkins, H. and Allen, C. I998. The relationship between staff burnout/distress and interactions with residents in two residential homes for older people, International Journal of Geriatric Psychiatry, 13, 446-72.

Kavanagh, S., Schneider, J., Knapp, M., Beecham, J. and Netten, A. i 993. Elderly people with cognitive impairment: costing possible changes in the balance of care, Health and Social Care, I, 69-80.

King's Fund r 986. Living Well into Old Age: Applying Principles of Good Practice to Services for People with Dementia. King's Fund, London.

Kitwood, T. i 997. Dementia Reconsidered: The Person Comes First. Open University Press, Buckingham. 
Kitwood, T. and Bredin, K. I992. Towards a theory of dementia care: personhood and well-being, Aging and Society, 12, 269-87.

Kitwood, T., Buckland, S. and Petrie, T. I995. Brighter Futures. Anchor Trust, Kidlington, Oxfordshire.

Kitwood, T. and Woods, B. I996. Training and Development Strategy for Dementia Care in Residential Settings. University of Bradford, Bradford, Yorkshire.

Laing and Buisson. 1998. Care of Elderly People: Market Survey 1998. Laing and Buisson, London.

Lawton, P. i 987 . Foreword. In Willcocks, D., Peace, S. and Kellaher, L. (eds), Private Lives in Public Places. Tavistock, London.

Lee-Treweek, G. I997. Emotion work, order and emotional power in care assistant work. In James, N. (ed.), The Sociology of Health and the Emotions. Blackwell, Oxford.

Lintern, T., Woods, B. and Phair, L. 20oo. Before and after training: a case study of intervention, Fournal of Dementia Care, 8, I 5-1 7 .

Lyman, K. I989. Bringing the social back in: a critique of the biomedicalization of dementia, The Gerontologist, 29, 5, 597-605.

Max, W. r 998. Cost of illness of dementia. In Wimo, A., Jonsson, B., Karlsson, G. and Winbald, B. (eds), Health Economics of Dementia. Wiley, Chichester, I 97-206.

McCallion, P., Toseland, R. W., Lacey, D. and Banks, S. I999. Educating nursing assistants to communicate more effectively with nursing home residents with dementia, The Gerontologist, 39, 5, 546-58.

McKee, K. I999. This is your life: research paradigms in dementia care. In Adams, T. and Clarke, C. L. (eds), Dementia Care: Developing Partnerships in Practice. Bailliere Tindall, London.

Means, R. and Smith, R. i 994. Community Care: Policy and Practice. Macmillan, London.

Moniz-Cook, E., Agar, S., Silver, M., Woods, R., Wang, M., Eltson, C. and Win, T. 1998. Can staff training reduce behavioural problems in residential care for the elderly mentally ill? International fournal of Geriatric Psychiatry, I3, I49-58.

Moos, R. H. and Lemke, S. i 984 . Multiphasic Environmental Assessment Procedure (MEAP) Manual. Social Ecology Laboratory, Stanford University, Palo Alto, California.

Morris, R. G., Woods, R. T., Davies, K. S. and Morris, L. W. i99I. Gender differences in carers of dementia sufferers, British Fournal of Psychiatry, I58, supplement io, 69-74.

Nolan, M., Grant, G. and Keady, J. i 996. Understanding Family Care. Open University Press, Buckingham.

Oldman, C. and Quilgars, D. I999. The last resort? Revisiting ideas about older people's living arrangements, Ageing and Society, r9, 363-84.

Parsons, W. i 995. Public Policy. Edward Elgar, Aldershot, Hampshire.

Patrick, D. L., Starks, H. E., Cain, K. C., Uhlmann, R. F. and Pearlam, R. M. I 994. Preferences for health states worse than death, Medical Decision Making, I4, 9-18.

Peace, S., Kellaher, L. and Willcocks, D. 1997. Re-evaluating Residential Care. Open University Press, Buckingham.

Phair, L. I 997. Sustaining and training nurses working in dementia care. Presentation given at RSAS Symposium-Dementia Care: Sustaining and Training Carers. Royal College of Physicians, London.

Post, S. i 993. Alzheimer disease and physician assisted suicide, Alzheimer's Disease and Associated Disorders, 7, 2, 65-8.

Raynes, N. I 999. Older residents, participation in specifying quality in nursing and residential care homes, Generations Review, 9, 2, Iо-I 2.

Royal College of Nursing. i 997. What a Difference a Nurse Makes. RCN, London.

Royal College of Physicians. I 992, I 999. The CARE Scheme (Continuous Assessment Review and Evaluation): Clinical Audit of Long-term Care of Elderly People. Royal College of Physicians, London. 
Royal Commission on Long Term Care. 1999. With Respect to Old Age: Long Term Care-Rights and Responsibilities. Stationery Office, London.

Sabat, S. and Harre, R. I992. The construction and deconstruction of self in Alzheimer's disease, Ageing and Society, I2, 443-6 I.

Sabat, S. and Collins, M. I999. Intact social, cognitive ability, selfhood: a case study of Alzheimer's disease, American fournal of Alzheimer's Disease, Jan/Feb, I I-I 9.

Sassi, F. and McDaid, D. (eds) i 999. Transnational Analysis of the Socio-economic Aspects of Alzheimer's Disease in the European Union. London School of Economics and Political Science, London.

Scottish Executive Press Release. 24 January 200 i. Free Care for Older People to be Extended in Scotland. www.scotland.gov.uk/news/200 I/o I/seo I 38.asp

Scottish Executive 200 r. National Care Standards: Care Homes for Older People. Scottish Executive, Edinburgh.

Stewart, A. I998. Alzheimer's disease: a review of current economic perspectives, Ageing and Society, 18, 585-6oo.

Tester, S. I999. The Quality Challenge: Caring for People with Dementia in Residential Institutions in Europe. European Commission and Alzheimer Scotland - Action on Dementia, Edinburgh.

Townsend, P. i 962. The Last Refuge. Routledge and Kegan Paul, London.

Ungerson, C. I987. Policy is Personal: Sex, Gender and Informal Care. Tavistock, London.

Wimo, A. Jonsson, B. Karlsson, G. and Winbald, B. (eds) r998. Health Economics of Dementia. Wiley, Chichester.

Woods, R. T. I989. Alzheimer's Disease: Coping with a Living Death. Souvenir, London.

World Health Organization. I 992. The ICD-IO: The International Classification of Diseases. Classification of Mental and Behavioural Disorders. WHO, Geneva.

Address for correspondence:

Accepted I Fanuary 2002

Anthea Innes, Department of Applied Social Science, Centre for Social Research on Dementia, University of Stirling, Stirling, FK9 $4 \mathrm{LA}$, Scotland.

e-mail: anthea.innes@stir.ac.uk 